\title{
Cryostat Slice Irregularities May Introduce Bias in Tissue Thickness Estimation: Relevance for Cell Counting Methods
}

\author{
Anna Puigdellívol-Sánchez, ${ }^{1,2, *}$ Albert Giralt,,${ }^{3,45}$ Anna Casanovas, ${ }^{6}$ Jordi Alberch, ${ }^{3,4,5}$ and \\ Alberto Prats-Galino ${ }^{1}$ \\ ${ }^{1}$ Human Anatomy and Embryology Unit, Facultat de Medicina, Universitat de Barcelona, c/Casanova 143, 08036 Barcelona, \\ Spain \\ ${ }^{2}$ CAP Anton de Borja, Consorci Sanitari de Terrassa, c/Edison-cantonada Marconi, 08091 Rubí, Barcelona, Spain \\ ${ }^{3}$ Departament de Biologia Cellular, Immunologia i Neurociències, Facultat de Medicina, Universitat de Barcelona, c/Casanova \\ 143, 08036 Barcelona, Spain. Barcelona, Spain \\ ${ }^{4}$ Institut d' Investigacions Biomèdiques August Pi i Sunyer (IDIBAPS), Universitat de Barcelona, c/Casanova 143, 08036 \\ Barcelona, Spain \\ ${ }^{5}$ Centro de Investigación Biomédica en Red sobre Enfermedades Neurodegenerativas, c/Casanova 143, 08036 Barcelona, Spain \\ ${ }^{6}$ Unit of Cellular Neurobioloy, Departament de Medicina Experimental, Facultat de Medicina, Universitat de Lleida, \\ c/Montserrat Roig 2, 25008 Lleida, Spain
}

\begin{abstract}
Stereological techniques using the optical disectors require estimation of final section thickness, but frozen tissue irregularities may interfere with this estimation. Cryostat slices from rodent nerve tissues (dorsal root ganglia, spinal cord, and brain), cut at 16,40 , and $50 \mu \mathrm{m}$, were digitized with a confocal microscope and visualized through 3D software. Geometric section thickness of tissue $\left(T_{\text {geom }}\right)$ was defined as tissue volume/area. Maximal section thicknesses $\left(T_{\max }\right)$, from the top to the bottom of the section, were measured in a random sample of vertical $Z X$ planes. Irregularities were mostly related to blood vessels traversing the tissue and neuronal somas protruding over the cut surfaces, with other neuron profiles showing a fragmented appearance. Irregularities contributed to increasing the distance between the tops and bottoms of slices sectioned in different laboratories. Significant differences were found between $T_{\max }$ and $T_{\text {geom }}$ for all thickness studies and counting frames $(p<0.01)$. The $T_{\text {geom }} / T_{\max }$ average rate was $68.4-85.7 \%$ in volumes around cell profiles $\left(\sim 600-1,200 \mu \mathrm{m}^{2}\right)$ and $83.3-91.8 \%$ in subcellular samples $\left(\sim 25-160 \mu \mathrm{m}^{2}\right)$. Confocal microscopy may help to assess tissue irregularities, which might lead to an overestimation of tissue volume if section thickness is estimated by focusing on the top and bottom of the sections.
\end{abstract}

Key words: quantitative microscopy, frozen sections, confocal microscopy, 3D analysis

\section{INTRODUCTION}

Estimation of cell populations in optical microscopy is potentially affected by the splitting of cells and their corresponding particles (nuclei or nucleoli) that may result when sectioning the tissue. If this occurs, the final number of visible profiles counted will be greater than the true number of cells, resulting in an overestimation of the studied population. Stereological techniques were designed to deal with this problem (see Dorph-Petersen \& Lewis, 2011 for a review).

Among modern stereological methods, the most popular is the optical disector (Gundersen et al., 1988), which is now automatic and counts particles in a known 3D fraction of tissue inside a thick slice (Howard et al., 1985). This fraction does not include the upper and lower surfaces (Williams \& Rakic, 1988) where irregularities and lost caps are thought to occur. In the optical disector, it is necessary to know the final section thickness of the studied slice.

Received October 1, 2014; accepted May 28, 2015

${ }^{*}$ Corresponding author. apuigdellivol@ub.edu
Section thickness has been commonly estimated by visualizing the upper and lower surface of the slice and measuring the difference by means of the microcator (Konigsmark, 1970; Coggeshall et al., 1990; Andersen \& Gundersen, 1999; Dorph-Petersen et al., 2001; Bermejo et al., 2003; Gardella et al., 2003; Baryshnikova et al., 2006; Rafati et al., 2013; Zhao et al., 2013). However, this way of estimating thickness might be impaired by the different focusing capacity of the observer's eye (Guillery, 2002) and excessively early or late recognition of the top or bottom of a section (Dorph-Petersen et al., 2001) if the tissue is markedly irregular. Intra-section thickness variations of only $0.3 \mu \mathrm{m}$ for individual glycol methacrylate sections and $1-3 \mu \mathrm{m}$ for individual paraffin sections have already been described (Helander, 1983). However, the marked, uneven shrinkage of frozen sections (Bonthius et al., 2004; Ward et al., 2008; Carlo \& Stevens, 2011), resulting in section deformations, has been reported to introduce substantial noise in the number estimates when unbiased stereological methods are used (Negredo et al., 2004). Frozen sections are commonly used in many nervous system studies and have been proposed for peripheral selective regeneration 
assessment with several fluorescent dyes (Puigdellívol-Sánchez et al, 2006; Ruiter et al., 2014).

This confocal microscopy-based study was designed to assess the irregularities in cryostat sections, and how they affect stereological counts.

\section{Material And Methods}

In order to reduce animal suffering, the examined frozen slices were obtained from material used in other studies kindly provided by different laboratories, including parvalbumin-labeled cells or Nissl staining from brains of mice (Giralt et al., 2010; UB-Biol Laboratory), motoneurons of mouse lumbar L2-L4 spinal cord (SC) labeled with cholera toxin subunit B-Alexa Fluor 488 conjugate (CT-488; Molecular Probes, Eugene, OR USA), or sections from rat lumbar SC (Casanovas et al., 2008; UdL-Anat Laboratory) and Diamidino Yellow- and Fast Bluelabeled dorsal root ganglion (DRG) cells and SC tissue (UBAnat Laboratory). Additional Sprague-Dawley rats $(n=8$, Harlan Interfauna Iberica SA, Sant Feliu de Codines, Spain) received subcutaneous injections of $0.5 \mu \mathrm{l}$ of $5 \%$ Fast Blue (FB, Sigma, St Louis, MO USA) or 5\% Diamidino Yellow (DY, EMS-Polyloy, Groß-Umstadt, Germany) in different hindlimb digits as previously described (Puigdellívol-Sánchez et al., 2006; UB-Anat Laboratory). All procedures followed the European Community guidelines for the care and use of laboratory animals (86/609//EEC) and Generalitat de Catalunya (DOGC 2073, 1995). Experiments were approved by the local animal care committee of Universitat de Barcelona (182/09), and Generalitat de Catalunya (99/1094).

All the animals of the present study were intracardially perfused with $4 \%$ paraformaldehyde in $0.1 \mathrm{M}$ phosphate buffer. Details of tissues examined, postfixation, cryoprotection, knives/blades, section thickness, section collection on the slide and immersion medium are found in Table 1.

\section{Confocal Microscopy}

Slices were examined at different postsectioning periods (t0-t30 days, Fig. 5) under a Leica TCS SP5 laser scanning confocal microscope (Leica Microsystems Heidelberg $\mathrm{GmbH}$, Mannheim, Germany), equipped with a DMI60/00 inverted microscope and XCS PL APO CS $63 \times$ glycerol objective (NA 1.3) for slices (1.466 refractive index) with aqueous mounting medium, using a $20 \% \mathrm{H}_{2} \mathrm{O}-80 \%$ glycerol immersion media. Images of $512 \times 512$ pixels with a pixel size of $0.48 \times 0.48 \mu \mathrm{m}\left(246 \times 246 \mu \mathrm{m}^{2}\right)$ were taken at 8 bits for randomly selected unlabeled tissue and at 12 bits for randomly selected slices with visible FB-DY-labeled cells, with a $0.3 \mu \mathrm{m}$ interval in $Z$. An APO lambda blue $63 \times$ oil immersion objective lens (NA 1.4) and oil immersion medium (1.518 refractive index) were used for DPXmounted slices in comparable acquisition conditions. Focusing through sections was performed against gravity. Point spread function (PSF) was assessed routinely by the confocal staff using $170 \mathrm{~nm}$ microspheres (PS-Spect TM microscope point source kit; Molecular probes, Eugene, OR USA), analyzed using the ImageJ program (Schneider et al., 2012) and Metroloj plugin (Matthews \& Cordelieres, 2010), resulting in a measured resolution at the full-width at half maximum of $331 \mathrm{~nm}$ (lateral resolution) and $881 \mathrm{~nm}$ (axial resolution) for the glycerol objective and $270 \mathrm{~nm}$ (lateral resolution) and $680 \mathrm{~nm}$ (axial resolution) for the oil objective. Refraction was assessed calculating the ratio of the visible distance between two coverslips separated by tested mounting media and immersion oil, resulting in 1.060-1.057 for $10-20 \%$ PBS in 90-80\% glycerol, respectively. Addition of antifading $1 \%$ paraphenylendiamine resulted in ratios of 1.052 and 1.058, respectively. Maximum "smart gain" was set just below image saturation levels, while minimal "smart offset" was set just below emptiness to ensure that the grayscale range included the whole range of the visible parts of the tissue.

Table 1. Details of Materials, Cryoprotection, Sectioning, and Immersion Medium.

\begin{tabular}{|c|c|c|c|c|c|c|c|}
\hline Laboratory & Animal & Tissue & $\begin{array}{l}\text { Post } \\
\text { Fixation }\end{array}$ & Cryoprotection & Knives/Blades & $\begin{array}{l}\text { Section Thickness } \\
(\mu \mathrm{m}) / \text { Collection }\end{array}$ & Immersion Medium \\
\hline \multirow[t]{2}{*}{ UB-Anat } & $\begin{array}{l}\text { Sprague- } \\
\text { Dawley } \\
\text { Rat }\end{array}$ & $\begin{array}{l}\text { DRG } \\
\text { L3-L6 }\end{array}$ & $2 \mathrm{~h}$ & $\begin{array}{l}\text { 15\% sucrose in } \\
\text { PB overnight }\end{array}$ & Reichert Jung knives & $16,40,50$ & $\begin{array}{l}10-20 \% \text { PBS in } \\
\text { glycerol }-1 \% \text { PPD }\end{array}$ \\
\hline & & SC & & & & $\begin{array}{c}40,50 \\
\text { Directly on } \\
\text { the slide }\end{array}$ & \\
\hline UdL-Anat & Mice/Rat & SC & Overnight & $\begin{array}{l}30 \% \text { sucrose in } \\
0.1 \mathrm{M} \mathrm{PB}\end{array}$ & $\begin{array}{l}\text { Stainless steel blades } \\
\text { (Feather Safety } \\
\text { Razor) }\end{array}$ & $\begin{array}{l}16 / 40,50 \\
\text { Directly on the } \\
\text { slide }\end{array}$ & $20 \%$ PBS in glycerol \\
\hline UB-Biol & Mice & Brain & $2 \mathrm{~h}$ & $\begin{array}{l}30 \% \text { sucrose in } \\
\text { PBS with } \\
0.02 \% \text { sodium } \\
\text { azide }\end{array}$ & $\begin{array}{l}\text { MX35 Premier } \\
\text { blades (Thermo } \\
\text { Scientific) }\end{array}$ & $\begin{array}{l}\text { 30, } 40,50 / \text { Directly } \\
\text { on the slide } \\
\text { 30/Free floating }\end{array}$ & $\begin{array}{l}\text { 20\% PBS in glycerol } \\
\text { DPX, after } \\
\text { dehydration and } \\
\text { Nissl or Parvalbumin } \\
\text { processing }\end{array}$ \\
\hline
\end{tabular}

DRG, dorsal root ganglion; L3-L6, corresponding lumbar levels; SC, spinal cord; PB, phosphate buffer; PBS, phosphate buferred saline; PPD, paraphenylendiamine. 

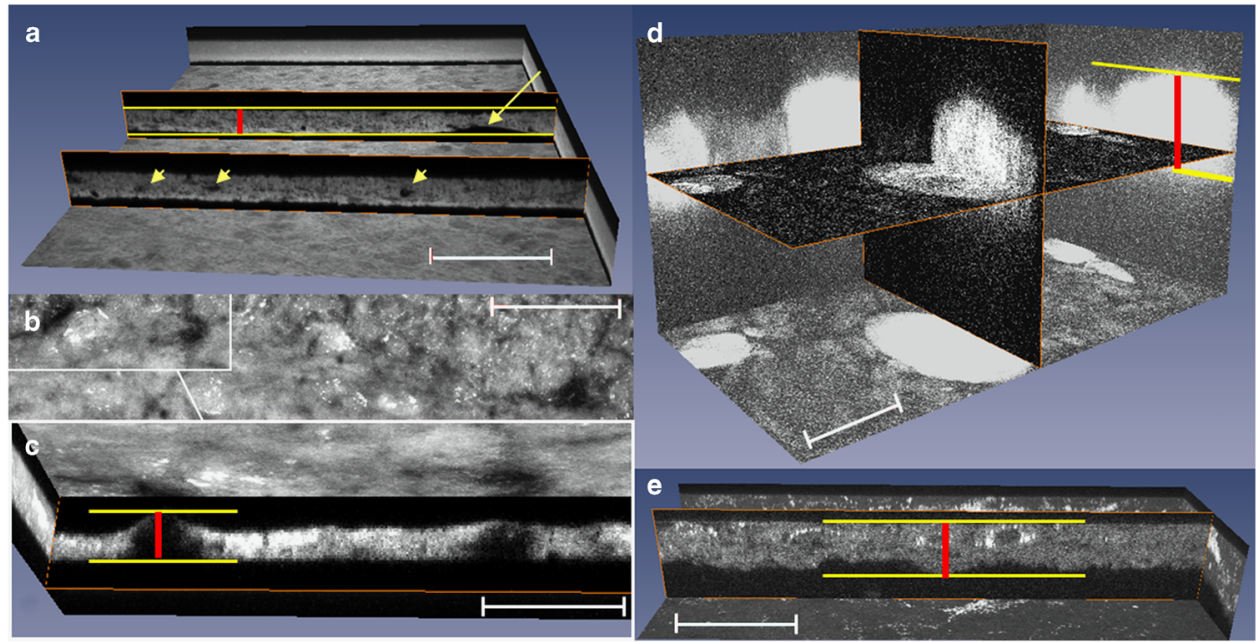

Figure 1. Tissue irregularities and protruding cell bodies. Frozen slices of nerve tissues from different laboratories and immersing mounting media showing irregularities. Projection views, $Z X, Z Y$, or $X Y$ planes and 3D reconstructions of samples of tissue. Yellow bars: top and bottom of the tissue slices: brain (UB biol; a, b, c), dorsal root ganglia, DRG (UB-Anat; d) and spinal cord (UdL Anat; e) slices. Red lines: $T_{\max }$. a: Nissl staining. Arrows indicate blood vessels within the tissue that cause irregularities at its entrance (long arrow). b: Mouse brain with parvalbumin-labelled cells. c: Detail of parvalbumin cells in mouse brain protruding in the surface of a vertical plane. d: Rat DRG in aqueous mounting medium. Labelled cells protruding in the upper surface. e: Rat spinal cord with autofluorescent motoneurons. Scale bar: (a, b, e) $50 \mu \mathrm{m}$ and (c and d) $20 \mu \mathrm{m}$.

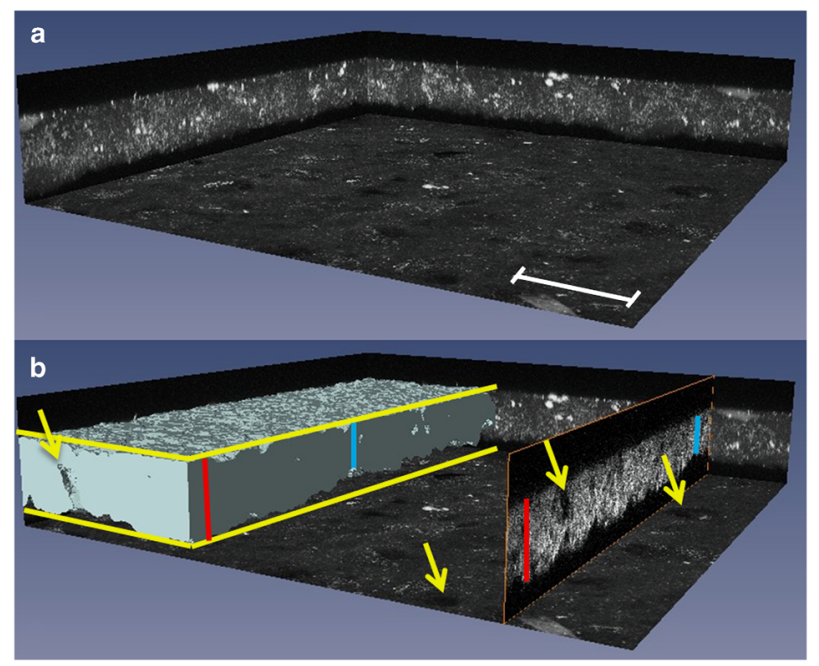

Figure 2. a: Irregularities within apparently homogeneous slices. Projection view of a $246 \times 246 \mu \mathrm{m}$ piece of digitized spinal cord tissue of an apparent homogeneous shape. Scale bar is $50 \mu \mathrm{m}$. b: Same slice at same magnification. Yellow lines: Top and bottom of the tissue. Red lines: $T_{\max }$. Blue lines: $T_{\min }$. Similar slice to a, including visualization of a $Z Y$ confocal plane on the right side and partial $3 \mathrm{D}$ reconstruction of tissue on the left, evidencing a less homogeneous tissue. Yellow arrows indicate blood vessels.

Images were acquired sequentially using $458 \mathrm{~nm}$ Argon laser lines and DPSS $561 \mathrm{~nm}$ laser lines, AOBS as beam splitter, emission detection ranges $415-515 \mathrm{~nm}$ and $570-700 \mathrm{~nm}$ and the confocal pinhole set at 1 Airy unit.

\section{Three-Dimensional Analysis and 3D Reconstruction}

Confocal files were analyzed using Amira 5.2 software (Mercuri Co. Boston, USA). Projection views and $X Z$ or $Y Z$ planes were examined (Fig. 1). Tissues, fibers and neuron profiles were visible due to their labeling or autofluorescence. A systematic random sample of $Z X$ planes of all digitizations ( $n=5$ for each sample of tissue) was selected for measurement of maximum $\left(T_{\max }\right)$ and minimum $\left(\mathrm{T}_{\min }\right)$ visible thicknesses in each plane (Fig. 2). Labeled cells and nuclei profiles were visualized in the three planes (Fig. 3).

A three-dimensional reconstruction of the digitized tissue sample was performed by semiautomatically choosing segmentation thresholds that select existing tissue and applying additional smoothing filters. The resulting reconstruction was examined in all spatial planes to ensure that the final reconstruction reliably reproduced the tissue shape.

The total volume of the reconstructed structure was then obtained. An estimated "Mean geometric section thickness" $\left(T_{\text {geom }}\right)$ was calculated for each $3 \mathrm{D}$ reconstruction or digitized tissue $\left(246 \times 246 \mu \mathrm{m}, 60,516 \mu \mathrm{m}^{2}\right)$ and for smaller samples around visible cell bodies ( $n=6$ per tissue sample; 600$1,200 \mu \mathrm{m}^{2}$ ) and subcellular samples within each cell sample (25-160 $\mu \mathrm{m}^{2}$ Fig. 4 and Table 3), and was defined as

Mean geometric section thickness $\left(T_{\text {geom }}\right)=$ volume $\left(\mathrm{mm}^{3}\right) /$ area $\left(\mathrm{mm}^{2}\right)$.

\section{Results}

Irregularities in the surfaces of the frozen sections were seen in all samples and laboratories (Fig. 1), corresponding 


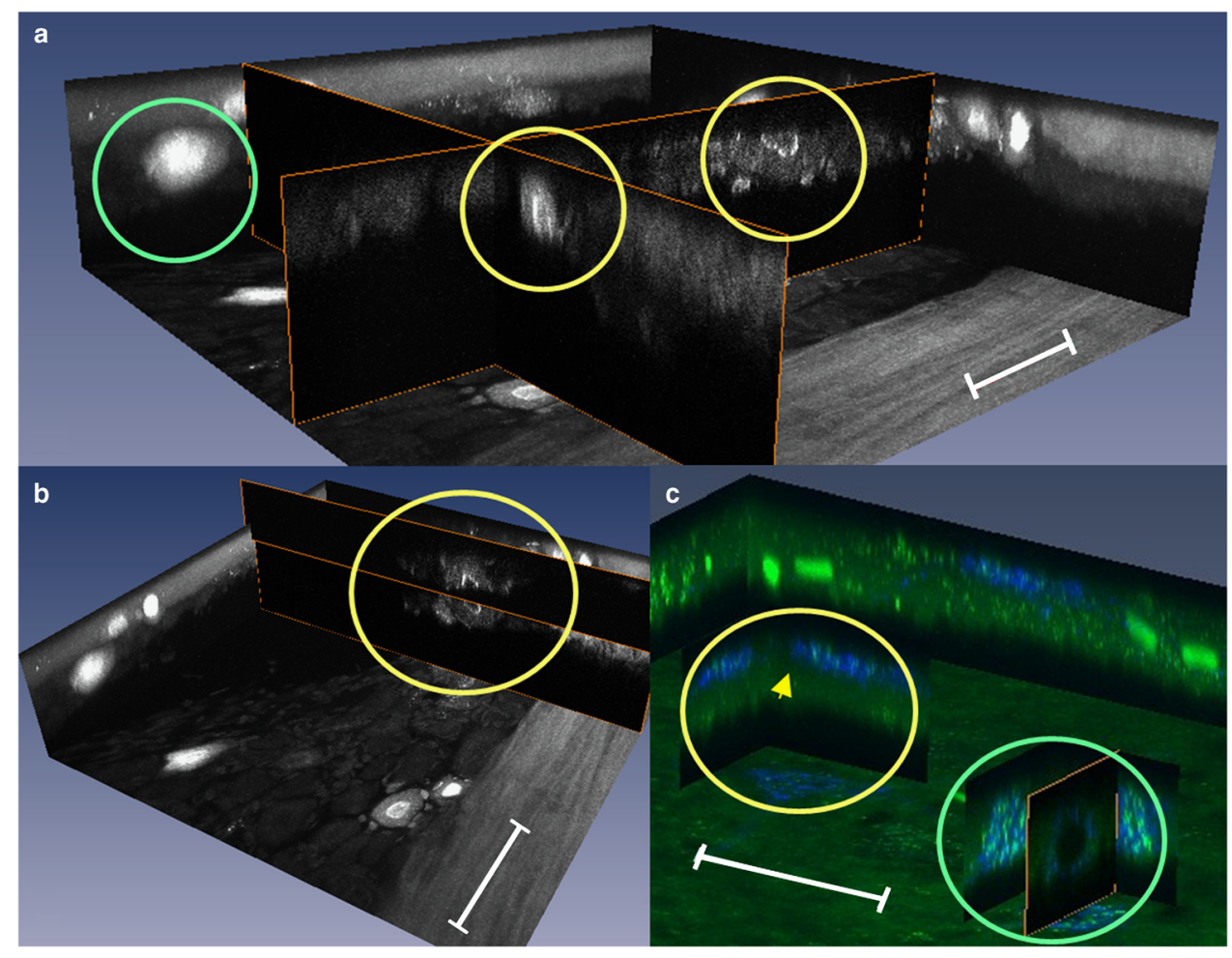

Figure 3. Cell splitting and complementary adjacent profiles. $16 \mu \mathrm{m}$ cut slices: a: Diamidino Yellow-labelled nuclei in the DRG tissue boundary (UB-Anat) with a slightly fractioned appearance (yellow circles) while another appears complete (green circle). b: Aligned planes of consecutive sections suggest that the nuclear profile is the complementary adjacent part of the same nucleus. c: Projection view of a sample of spinal cord tissue (UdL-Anat) and of subsamples including CT-488 blue-labelled motoneurons. One is fractioned (yellow circle) in the upper surface of the slice (arrowhead) and the other is complete (green circle). Scale bar is $50 \mu \mathrm{m}$.

in some instances to blood vessels traversing the tissue (Fig. 1a) and also to some protruding neuronal cell bodies (Figs. 1c, 1d). The surface facing the glass slide tended to appear more flattened.

Even when projection views show an apparent homogenous shape of the tissue slice (Fig. 2a), 3D reconstruction of the digitized tissue confirms the presence of tissue irregularities (Fig. 2b). These irregularities (Figs. 1 and 2) increase the distance (red lines) between tops and bottoms of the section (yellow lines) in all the samples from the different laboratories.

Individual visualization of nuclei profiles in $16 \mu \mathrm{m}$ thick DRG or SC slices (98 DRG nuclear profiles and 27 SC motoneuron profiles) revealed undivided nuclei and cells, others with a fragmented appearance (12 and 59\%, respectively, Figs. 3a, 3c) and some with an identifiable complementary profile in the adjacent slice (2 and 23\% respectively; Fig. 3b). Visualization of parvalbumin-labeled brain neurons also showed cells without any apparent fragmentation of the cell body (Fig. 1c).

Differences between $\mathrm{T}_{\max }$ and $\mathrm{T}_{\text {min }}$, measured in the same $X Y$ or $X Z$ planes (Fig. $2 b$ ), were significant ( $p$ range $=0.00001-0.049$ ) for all the section thicknesses (Table 2), mounting media and postsectioning periods compared. Measurements digitized on the same day as tissue sectioning are summarized in Table 2 while those digitized later showed
$T_{\text {geom }}$ reductions of up to $51 \%$ at $t 30$ days compared with $t 0$ measurements (Fig. 5).

Significant differences were found between $T_{\max }$ and $T$ geom for all thickness studies and counting frames, when quantified in smaller samples around visible cell bodies and also in corresponding subsamples (Figs. $4 \mathrm{~b}, 4 \mathrm{c}$, respectively) selected within the soma sample $(p<0.00005-0.01)$. The area in samples and subsamples was comparable to the counting frame used in stereological studies, where the $T_{\text {geom }} / T_{\max }$ ratio showed a range of $68-92 \%$ (Table 3).

\section{Discussion}

\section{Tissue Irregularities}

Irregularities are known to occur in frozen slices (DorphPetersen et al., 2001; Gardella et al., 2003; Bonthius et al., 2004; Ward et al., 2008), but no previous confocal studies have directly assessed this phenomenon. These irregularities, including neuronal somas protruding over the surfaces of the cut tissue or blood vessels traversing the tissue were seen in DRG, SC, or brain slices from the different cryostats, blades, and laboratories. Optical disector measurements in the central part of a thick section were introduced to avoid such interference (Williams \& Rakic, 1988) while modified 
Table 2. Measures at $t 0$ Post-Cutting.

\begin{tabular}{|c|c|c|c|c|c|c|}
\hline Case & $\mu \mathrm{m}$ cut thickness & $T_{\text {geom. }}(\mu \mathrm{m})$ & $T_{\max }(\mu \mathrm{m})$ & $T_{\min }(\mu \mathrm{m})$ & $p T_{\max }$ versus $T_{\min }$ & $T_{\text {geom }} / T_{\text {max }}$ \\
\hline DRG 014 & 16 & 15.3 & $27.6 \pm 2.8$ & $10.1 \pm 1.4$ & 0.003 & 0.55 \\
\hline DRG 011 & 40 & 44.5 & 53. $6 \pm 4.2$ & $36.3 \pm 4.2$ & 0.002 & 0.83 \\
\hline DRG 012 & 50 & 46.9 & $51.7 \pm 4.1$ & $34.7 \pm 2.3$ & 0.006 & 0.90 \\
\hline SC 013 & 40 & 43.1 & $48.4 \pm 11.2$ & $37.1 \pm 1.8$ & 0.0007 & 0.89 \\
\hline BR 093 & 30 & 32.6 & $34.4 \pm 0.8$ & $31.8 \pm 0.9$ & 0.009 & 0.94 \\
\hline BR 094 & 40 & 41.9 & $42.3 \pm 0.3$ & $39.6 \pm 1.2$ & 0.007 & 0.99 \\
\hline BR 095 & 50 & 53.2 & $53.4 \pm 1.2$ & $51.2 \pm 0.7$ & 0.047 & 0.99 \\
\hline
\end{tabular}

DRG, dorsal root ganglia; SC, spinal cord; BR, brain.

$T_{\text {geom }}$ is calculated for the whole piece of sampled tissue $\left(60,516 \mu \mathrm{m}^{2}\right) \cdot T_{\max }$ and $T_{\min }$ are measured in a systematic random sample of $5 \mathrm{ZX}$ planes $(X: 246 \mu \mathrm{m})$ inside the digitized tissue piece. Means \pm standard deviation are presented. Significant differences $(p)$ between those parameters and the relationship $T_{\text {geom }} / T_{\max }$ are detailed.
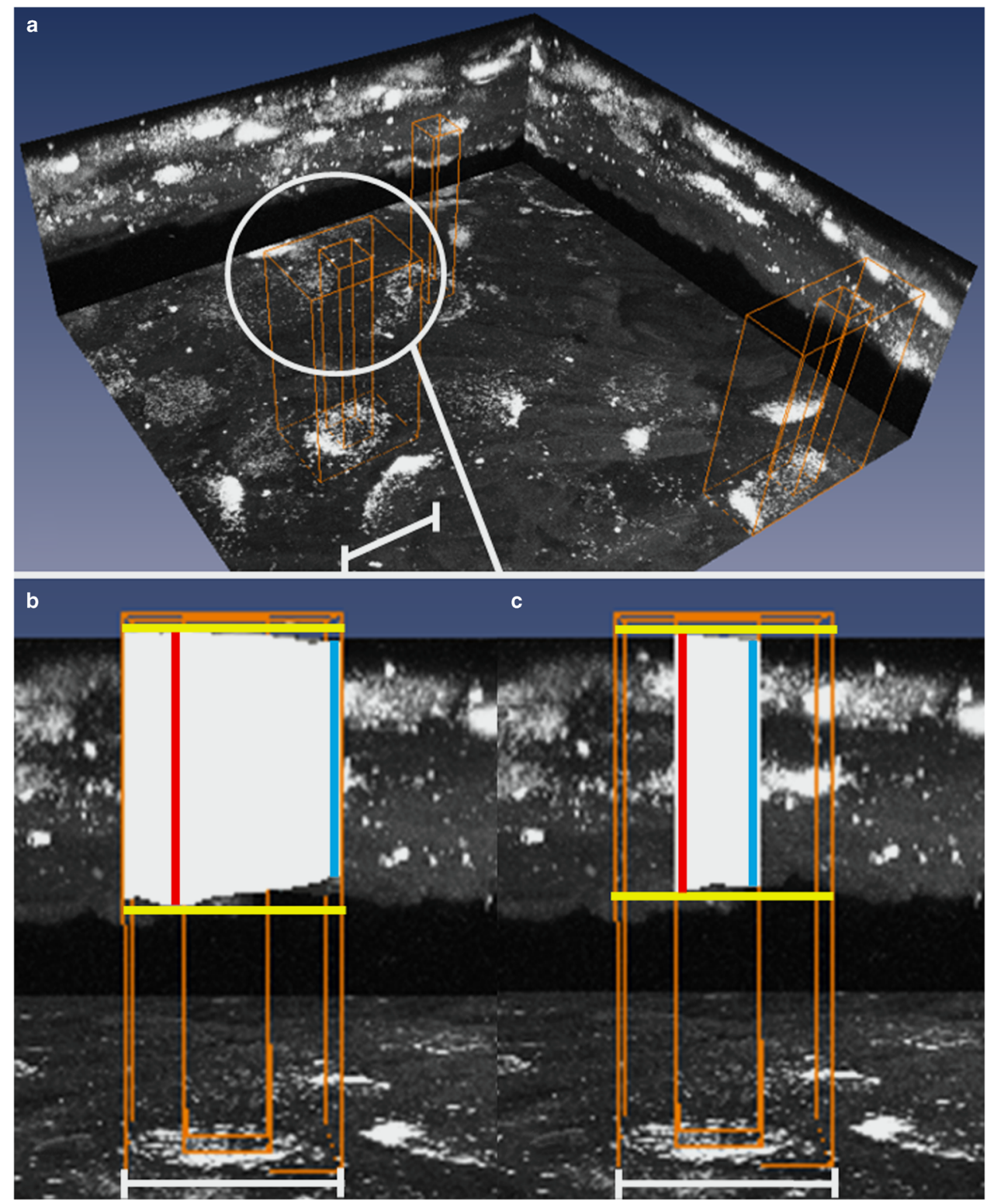

Figure 4. Measures in tissue subsamples. a: Projection view of a $246 \times 246 \mu \mathrm{m}$ piece of dorsal root ganglion tissue. Orange prisms around cell bodies are sampled, with subsamples inside, where volumes, $T_{\max }$ and $T_{\min }$ will be calculated. b: $3 \mathrm{D}$ reconstruction of tissue (in white) within the prism around a cell body $(42 \times 32 \mu \mathrm{m}$ area). c: $3 \mathrm{D}$ reconstruction of tissue within the subsample $\left(12 \times 13 \mu \mathrm{m}\right.$ area). Yellow lines: Top and bottom of the tissue. Red lines: $T_{\max }$. Blue lines: $T_{\min }$. Notice that the red distance is greater than the real tissue thickness. Scale bar is $42 \mu \mathrm{m}$. 


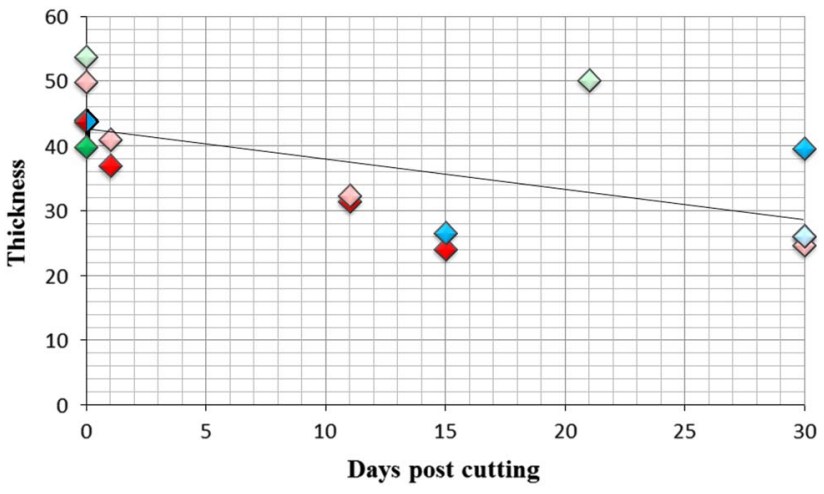

Figure 5. Average estimated thickness in 40 and $50 \mu \mathrm{m}$ cut tissue samples (strong and pale colors, respectively) digitized at different time points post cutting (0-30 days). DRG samples in red, SC in blue and brain in green. Note the trend towards reduced average thickness with time.

disector including sampling of the whole section has also been proposed (Hatton \& Von Bartheld, 1999; Carlo \& Stevens, 2011).

The presence of some fractioned labeled nuclei, without identification of the fractioned nuclei portion in the adjacent DRG slice, might suggest a certain fragment loss but also the impossibility of visualizing small fractions in the consecutive section (suggested by Floderus, 1944; cited in Haug, 1986 and others). The possible occurrence of lost caps in slide surfaces has been proposed (Andersen \& Gundersen, 1999) and it has been suggested that they may interfere in the different counting methods analyzed (Hedreen, 1998; Heller et al., 2001). However, the visualization of protruding cell bodies in the frozen slices may also explain the existence of corresponding "holes" in the adjacent section.

\section{Section Thickness Estimation}

The current way of estimating section thickness visualizing the upper and lower surface of the slice (Konigsmark, 1970; Coggeshall et al., 1990; Andersen \& Gundersen, 1999; Dorph-Petersen et al., 2001; Bermejo et al., 2003; Gardella et al., 2003; Baryshnikova et al., 2006; Rafati et al., 2013; Zhao et al., 2013) may be comparable to estimating the distance between lines located at the top and bottom of the sections in the different figures, here considered as $T_{\max }$, that would be above final averaging section thickness, here proposed as $T_{\text {geom. }}$. Although the variable extent of such differences may be due to the different tissue sources and cutting knives and blades, the difference between $T_{\max }$ and $T_{\text {geom }}$ is significant in the different types of tissues examined. Previous studies have assessed the axial shrinkage by means of confocal microscopy (Janáček et al., 2012). Here, we introduce the $T_{\text {geom }}$ proposal to estimate an average section thickness.

The absolute measures of $T_{\text {geom }}$ and $T_{\max }$ must be considered with caution, as they are affected by the refractive phenomena of the different immersion media (Hell et al., 1993; Kuypers et al., 2005) and of the tissue studied (Franze et al., 2007)-about $6 \%$ here, maximum $3 \mu \mathrm{m}$ in wider samples in aqueous mounting media. The recommendation is that it should be directly assessed in each situation. Furthermore, the PSF effect is negligible in those samples (causing $<1 \mu \mathrm{m}$ of bias). Thus, since refraction of lasers would have an equal effect on the absolute estimation of $T_{\max }$ and $T_{\text {geom }}$, their relationship would be consistent, and indicative of the maximal possible bias when using $T_{\max }$ in the disector formula. It is suggested that the combined measurements should be performed on the same day when using aqueous mounting media, due to the progressive shrinkage that may occur after a certain degree of drying during no-frost freezer storage. Future work is needed to

Table 3. $T_{\max }$ and $T_{\text {geom }}$ in Tissue Subsamples.

\begin{tabular}{|c|c|c|c|c|c|}
\hline Tissue thickness & $T_{\text {geom }}$ & $T_{\max }$ & Area $\left(\mu \mathrm{m}^{2)}\right.$ & $T_{\text {geom }} / T_{\max }$ & $p T_{\text {geom }}$ versus $T_{\max }$ \\
\hline \multicolumn{6}{|l|}{ Soma samples } \\
\hline DRG $16 \mu \mathrm{m}$ & $19.9 \pm 1.3$ & $29.1 \pm 2.6$ & $888.9 \pm 196.0$ & $68.4 \% \pm 4.6 \%$ & 0.0001 \\
\hline DRG $40 \mu \mathrm{m}$ & $41.1 \pm 6.4$ & $50.3 \pm 8.7$ & $1,260.8 \pm 350.8$ & $84.2 \% \pm 4.2 \%$ & 0.002 \\
\hline DRG $50 \mu \mathrm{m}$ & $47.3 \pm 5.0$ & $58.3 \pm 7.3$ & $2,173.6 \pm 654$ & $81.7 \% \pm 8.4 \%$ & 0.007 \\
\hline $\mathrm{SC} 40 \mu \mathrm{m}$ & $44.1 \pm 3.2$ & $51.4 \pm 3.4$ & $494.8 \pm 145.3$ & $85.7 \% \pm 4.3 \%$ & 0.0006 \\
\hline $\mathrm{SC} 16 \mu \mathrm{m}$ & $18.7 \pm 1.1$ & $23.4 \pm 1.1$ & $1,261.8 \pm 490.3$ & $80.1 \% \pm 6.3$ & 0.0008 \\
\hline Brain Parvalbumin & $7.5 \pm 0.2$ & $10.2 \pm 0.5$ & $632.5 \pm 80.1$ & $74.3 \% \pm 3.6 \%$ & 0.00005 \\
\hline \multicolumn{6}{|l|}{ Subcellular samples } \\
\hline DRG $16 \mu \mathrm{m}$ & $22.9 \pm 1.7$ & $26.9 \pm 1.7$ & $134.4 \pm 21.2$ & $84.8 \% \pm 2.9 \%$ & 0.00008 \\
\hline DRG $40 \mu \mathrm{m}$ & $40.9 \pm 6.3$ & $45.5 \pm 6.8$ & $158.3 \pm 28.8$ & $90.1 \% \pm 5.4 \%$ & 0.01 \\
\hline DRG $50 \mu \mathrm{m}$ & $49.7 \pm 6.9$ & $56.5 \pm 6.2$ & $221.2 \pm 42.9$ & $88.1 \% \pm 7.6 \%$ & 0.01 \\
\hline $\mathrm{SC} 40 \mu \mathrm{m}$ & $44.9 \pm 5.2$ & $48.8 \pm 4.5$ & $26.7 \pm 3.5$ & $91.8 \% \pm 3.7 \%$ & 0.002 \\
\hline $\mathrm{SC} 16 \mu \mathrm{m}$ & $18.1 \pm 2.5$ & $21.8 \pm 1.9$ & $76.2 \pm 29.2$ & $83.3 \% \pm 11.2$ & 0.01 \\
\hline Brain Parvalbumin & $6.9 \pm 0.6$ & $8.3 \pm 0.9$ & $57.7 \pm 10.1$ & $83.5 \% \pm 5.6 \%$ & 0.002 \\
\hline
\end{tabular}

DRG, dorsal root ganglion; SC, spinal cord.

$T_{\max }$ and $T_{\text {geom }}$ were measured in 3D cubes sampled around visible neuron cell bodies ( $n=6$ per tissue) inside the digitized pieces of tissue. Additional cubes were subsampled inside. The area studied is indicated, together with the relationship between $T_{\text {geom }}$ and $T_{\max }$ and their significant differences ( $p$ ) in all samples of tissue. 
assess the known deformations in other embedding techniques (Helander, 1983) and to determine the right sample of confocal measurements needed to "calibrate" an automated microcator approach.

\section{Counting Frames and the $T_{\text {geom }} / T_{\text {max }}$ Rate}

Different microscopy counting frames (Howard et al, 1985), the sample area where cells are estimated, have been used in stereological studies. The area of the subcellular samples (Fig. 4 and Table 3) was similar to the counting frames used in Bergman \& Ulfhake (1998): $39,828 \mu \mathrm{m}^{2}$; Bonthius et al. (2004): $324 \mu \mathrm{m}^{2}$; Van de Berg et al. (2002): $246 \mu \mathrm{m}^{2}$; as examples, while the soma-centered samples include sides of $34.4-39.4 \mu \mathrm{m}$, corresponding to area frames of $1,186-1,554$ $\mu \mathrm{m}^{2}$, similar to the counting frame used in Negredo et al. (2004), Christensen et al. (2007), and Dwork et al. (2009). Some studies have used wider frames of $18,100-18,900$ or $40,000 \mu \mathrm{m}^{2}$ if low objectives are used, with side lengths of $134.5-200 \mu \mathrm{m}$ (Messina et al., 2000; Gardi et al., 2008; Ibáñez-Sandoval et al., 2010), comparable to the whole sample of digitized tissue visualized through the $60 \times$ objective $(246 \times 246 \mu \mathrm{m}$, Fig. 2 and Table 2). Although the $T_{\text {geom }} / T_{\max }$ ratio is often above $90 \%$, it may reach $84 \%$ in the subsample area, $66 \%$ in samples around cell bodies and $55 \%$ in $246 \times 246 \mu \mathrm{m}$ tissue samples digitized at $t 0$. The area of the counting frame is related to the likelihood of including any irregularities affecting $\mathrm{T}_{\max }$. Significant differences between $T_{\max }$ and $T_{\text {geom }}$ have been found in all kinds of tissue samples and in cellular and subcellular samples of the different laboratories (Table 3 and Fig. 4). Thus, if the aim is to achieve higher precision and to reduce the potential overestimation of section thickness, small counting frames $\left(<200 \mu \mathrm{m}^{2}\right)$ could be used in samples with greater irregularities.

This procedure may allow a higher precision in section thickness estimates if desired. The current subjective estimation of thickness visualizing the top and bottom of the slice using an optical microscope is uncertain and is affected by the different focusing ability of the observers (Guillery, 2002).

Recommendations arising from this study would depend on the rate of cell splitting, the tissue shrinkage, and the degree of irregularity. Low splitting rates (knife-cut DRG samples) could explain the similarities between cell estimations from profile counts (Puigdellivol-Sánchez et al., 2006) and from systematic reconstruction of sciatic cell populations (Sweet et al., 1986, 1991). As decreases in thickness have been detected even 1 day after sectioning when mounted in aqueous mounting medium, it is important to perform counts on the day of tissue sectioning, especially in certain samples (here DRG and SC), although some unlabeled brain samples directly mounted on the slide showed less thickness shrinkage (Fig. 5, Table 2) while preliminary observations suggest that free-floating slices may also show differences from cut thickness at $t 0$, and more irregularities were detected in other brain-labeled samples (Fig. 1 and Table 3). The long time needed for digitization of high resolution $246 \times 246 \mu$ m-labelled samples-about
10 min per each 12 bit acquisition-limits the number of pieces of tissue that may be studied in a single day of combined stereological estimations. If the degree of irregularity $\left(T_{\max }-T_{\min }\right)$ is homogeneous between the samples acquired for any specific experimental design and tissue, the $T_{\text {geom }} / T_{\max }$ rate could be representative of the maximal bias for thickness estimation, and a range including the real data could be estimated. Volume quantification may be performed through free software (see 3D Image J Suite, for instance). Future work is needed to assess the tissue shrinkage during freezer versus refrigerator storage, with or without no-frost technology, depending on the mounting medium and tissue types.

\section{CONCLUSION}

Confocal microscopy may enhance the assessment of cell splitting and frozen slice irregularities. These irregularities may affect the estimation of section thickness that is needed in the disector method. If high precision is desired, taking into account refractive aspects, the use of confocal microscopy and $3 \mathrm{D}$ software allows the calculation of mean geometric section thickness.

\section{ACKNOWLEDGMENTS}

The authors thank Dolors Fuster for laboratory technical support and Kenneth Palma for some 3D tissue preliminary reconstructions. CIBERNED and Red de Terapia Celular (RD06 0010/0006). They thank Dr. Maria Calvo, Anna Bosch and Elisenda Roca from the Advanced Optical microscopy unit (Campus Clínic) for their support and advice with all confocal techniques. Authors declare no conflict of interest.

\section{REFERENCES}

Andersen, B.B. \& Gundersen, J.G. (1999). Pronounced loss of cell nuclei and anisotropic deformation of thick sections. J Microsc 196, 69-73.

Baryshnikova, L.M., Von Bohlen Und Halbach, O., Kaplan, S. \& Von Bartheld, C.S. (2006). Two distinct events, section compression and loss of particles ("lost caps"), contribute to $\mathrm{z}$-axis distortion and bias in optical disector counting. Microsc Res Tech 69, 738-756.

Bergman, E. \& UlfHAKe, B. (1998). Loss of primary sensory neurons in the very old rat: neuron number estimates using the disector method and confocal optical sectioning. J Comp Neurol 396, 211-222.

Bermejo, P.E., Jiménez, C.E., Torres, C.V. \& Avendaño, A. (2003). Quantitative stereological evaluation of the gracile and cuneate nuclei and their projection neurons in the rat. J Comp Neurol 463, 419-433.

Bonthius, D.J., Mc Kim, R., Koele, L., Harb, H., Karacay, B., Mahoney, J. \& Pantazis, N.J. (2004). Use of frozen sections to determine neuronal number in the murine hippocampus and neocortex using the optical disector and optical fractionator. Brain Res Protocols 14, 45-47. 
Carlo, C.N. \& Stevens, C.F. (2011). Analysis of differential shrinkage in frozen brain sections and its implications for the use of guard zones in stereology. J Comp Neurol 519, 2803-2810.

Casanovas, A., Hernández, S., Tarabal, O., Rosselló, J. \& EsqueRDA, J.E. (2008). Strong $\mathrm{P} 2 \times 4$ purinergic receptor-like immunoreactivity is selectively associated with degenerating neurons in transgenic rodent models of amyotrophic lateral sclerosis. J Comp Neurol 506, 75-92.

Christensen, J.R., Larsen, K.B., Lisanby, S.H., Scalia, J., Arango, V., Dwork, A.J. \& Pakkenberg, B. (2007). Neocortical and hippocampal neuron and glial cell numbers in the rhesus monkeys. Anat Rec 290, 330-340.

Coggeshall, R.E., La Forte, R. \& Klein, C.M. (1990). Calibration of methods for determining numbers of dorsal root ganglion cells. J Neurosci Methods 35, 187-194.

Dorph-Petersen, K.A., Neurosci Methods, J. \& Lewis, D.A. (2011). Stereological approaches to identifying neuropathology in psychosis. Biol Psychiatry 69, 113-116.

Dorph-Petersen, K.A., Nyengaard, J.R. \& Gundersen, H.J.G. (2001). Tissue shrinkage and unbiased stereological estimation of particle number and size. J Microsc 204, 232-246.

Dwork, A.J., Christensen, J.R., Larsen, K.B., Scalia, J., Underwood, M.D., Arango, V., Pakkenberg, B. \& Lisanby, S.H. (2009). Unaltered neuronal and glial counts in animal models of magnetic seizure therapy and electroconvulsive therapy. Neuroscience 164, 1557-1564.

Floderus, S. (1944). Untersuchungen über den Bau der menschlichen hypophyse mit besonderer Berücksichtigung der quantitativen mikromorphologischen Verhältnisse. Acta Pathol Microbiol Scan Suppl 53, 1-276.

Franze, K., Grosche, J., Skatchkov, S.N., Schinkinger, S., Foja, C., Schild, D., Uckermann, O., Travis, K., Reichenbach, A. \& Guck, J. (2007). Müller cells are living optical fibers in the vertebrate retina. Proc Natl Acad USA 104, 8287-8292.

Gardella, D., Hatton, W.J., Rind, H.B., Rosen, G.D. \& Von BARTheld, C.S. (2003). Differential tissue shrinkage and compression in the z-axis: Implications for optical disector counting in vibratome-, plastic-, and cryosections. J Neurosci Methods 124, 45-59.

Gardi, J.E., NyengaArd, J.R. \& Gundersen, H.J.G. (2008). Automatic sampling for unbiased and efficient stereological estimation using the proportionator in biological studies. J Microscopy 230, 108-120.

Giralt, A., Friedman, H.C., Caneda-Ferrón, B., Urbán, N., Moreno, E., Rubio, N., Blanco, J., Peterson, A., Canals, J.M. \& Alberch, J. (2010). BDNF regulation under GFAP promoter provides engineered astrocytes as a new approach for long-term protection in Huntington's disease. Gene Ther 17, 1294-1308.

GuilLeRY, R.W. (2002). On counting and counting errors. J Neurosci Methods 447, 1-7.

Gundersen, H.J.G., Bagger, P., Bendtsen, T.F., Evans, S.M., Korbo, L., Marcussen, N., Møller, A., Nielsen, K., NyengaArd, J.R., Pakkenberg, B., Sørensen, F.B., Vesterby, A. \& West, M.J. (1988). The new stereological tools: Disector, fractionator, nucleator and point sampled intercepts and their use in pathological research and diagnosis. APMIS 96, 857-881.

HaUG, H. (1986). History of neuromorphometry. J Neurosci Methods 18, 1-17.

Hatton, W.J. \& Von Bartheld, C.S. (1999). Analysis of cell death in the trochlear nucleus of the chick embryo: Calibration of the disector counting method reveals systematic bias. J Comp Neurol 409, 169-186.
Hedreen, J.C. (1998). Lost caps in histological counting methods. Anat Rec 250, 366-372.

Helander, K.G. (1983). Thickness variations within individual paraffin and glycol methacrylate sections. J Microsc 132, 223-227.

Hell, S., Reiner, G., Cremer, C. \& Stelzer, E.H.Z. (1993). Aberrations in confocal fluorescence microscopy induced by mismatches in refractive index. J Microsc 169, 391-405.

Heller, B., Schwingruber, F., Guvenc, D. \& Heller, A. (2001). Computer experiments to determine whether over-or undercounting necessarily affects the determination of difference in cell number between experimental groups. J Neurosci Methods 91, 91-99.

Howard, V., Reid, S., Baddeley, A. \& Boyde, A. (1985). Unbiased estimation of particle density in the tandem scanning reflected light microscope. J Microsc 138, 203-212.

IbáÑez-Sandoval, O., Tecaupetla, F., Unal, B., Shah, F., Koós, T. \& Tepper, J.M. (2010). Electrophysiological and morphological characteristics and synaptic connectivity of tyrosine hydroxylaseexpressing neurons in adult mouse striatum. J Neurosci 30, 6999-7016.

JanÁČeK, J., KREFT, M., CebašEK, V. \& ErŽEN, I. (2012). Correcting the axial shrinkage of skeletal muscle thick sections visualized by confocal microscopy. J Microsc 246, 107-112.

Konigsmark, B.W. (1970). Methods for the counting of neurons. In Contemporary Research Methods in Neuroanatomy, Nauta, W.J.H. \& Ebbesson, S.O.E. (Eds.), pp. 315-338. Berlin: Springer-Verlag.

Kuypers, L.C., Decraemer, W.F., Dirckwx, J.J. \& Timmermans, J.P. (2005). A procedure to determine the correct thickness of an object with confocal microscopy in case of refractive index mismatch. J Microsc 218, 68-78.

Matthews, C. \& Cordelieres, F.P. (2010). MetroloJ: An ImageJ plugin to help monitor microscopes' health. ImageJ User and Developer Conference. MetroloJ website. Available at http:// imagejdocu.tudor.lu/doku.php?id=plugin:analysis:metroloj:start. retrieved July 1, 2014.

Messina, A., SAngter, C.L., Morrison, W.A. \& Galea, M.P. (2000). Requirements for obtaining unbiased estimates of neuronal numbers in frozen sections. J Neurosci Methods 97, 133-137.

Negredo, P., Castro, J., Lago, N., Navarro, X. \& Avendaño, C. (2004). Differential growth of axons from sensory and motor neurons through a regenerative electrode: A stereological, retrograde tracer, and functional study in the rat. Neuroscience 128, 605-615.

Puigdellívol-Sánchez, A., Prats-Galino, A. \& Molander, C. (2006). Estimations of topographically correct regeneration to nerve branches and skin after peripheral nerve injury and repair. Brain Res 1098, 49-60.

Rafati, A., Noorafshan, A. \& Torabi, N. (2013). Stereological study of the effects of morphine consumption and abstinence on the number of neurons and oligodendrocytes in medial prefrontal cortex of rats. Anat Cell Biol 46, 191-197.

Ruiter, G.C., Spinner, R.J., Verhhagen, J. \& Malessy, M.J. (2014). Misdirection and guidance of regenerating axons after experimental nerve injury and repair. J Neurosurg 120, 493-501.

SChNeIdeR, C.A., RASBAND, W.S. \& Eliceiri, K.W. (2012). NIH Image to Image): 25 years of image analysis. Nat Methods 9, 671-675.

Swett, J.E., Wikholm, R.P., Blanks, R.H.I., Swett, A.L. \& Conley, L.C. (1986). Motoneurons of the rat sciatic nerve. Exp Neurol 93, 227-252.

Swett, J.E., Torigoew, Y., Elie, V.R., Bourassa, C.M \& Miller, P.,G. (1991). Sensory neurons of the rat sciatic nerve. Exp Neurol 114, 82-103. 
Van de Berg, W.D.J., Schmitz, C., Steinbusch, H.W.M. \& Blanco, C.E (2002). Perinatal asphyxia induced neuronal loss by apoptosis in the neonatal rat striatum: A combined TUNEL and stereological study. Exp Neurol 174, 29-36.

Ward, T.S., Rosen, G.D. \& Von Bartheld, C.S. (2008). Optical disector counting in cryosections and vibratome sections underestimates particle numbers: Effects of tissue quality. Microsc Res Tech 71, 60-68.
Williams, R.W. \& RAKIC, P. (1988). Three-dimensional counting: an accurate and direct method to estimate numbers of cells in sectioned material. J Comp Neurol 278, 344-352. Erratum in 1989, 281: 355.

Zhao, Y.Y., Shi, X.Y., Zhang, L., Wu, H., Chao, F.L., Huang, C.S., GaO, Y., Qiu, X., Chen, L., Lu, W. \& TAng, Y. (2013). Enriched environment induces higher CNPase positive cells in aged rat hippocampus. Neurosci Lett 555, 177-181. 